\title{
Egon Schiele como trickster: possíveis aproximações
}

\section{Resumo}

Egon Schiele, em seus autorretratos, investiga, com um olhar cuidadoso e extremamente crítico, o psicológico e o emocional e produz extensa obra em 10 anos. As ambiguidades e as várias transformações a que se sujeita permitem traçar paralelos entre suas obras e o trickster, mítica figura que transita entre fronteiras, cruzando seus limites, o trapaceiro, uma entidade de múltiplas formas.

Este artigo visa estudar o Autorretrato nu de Schiele de 1910, analisá-lo e esclarecer possíveis semelhanças encontradas a partir da comparação entre ele e as seis características do multicultural e multiformal trickster criadas por William Hynes e presentes no capítulo Mapping trickster characteristcs do livro Mythical Trickster Figures.

Palavras-chave: Egon Schiele, trickster, análise de imagens 


\title{
Egon Schiele as trickster: possible approaches
}

\author{
DANIEL FRANCO DE OLIVEIRA
}

\begin{abstract}
Egon Schiele, in his self-portraits, investigates, with a careful and extremely critical view, the psychological and emotional and produces an extense work in 10 years. The ambiguities and the many transformations in which he submits himself allow him to trace parallels between his work and the trickster, a mythic figure who transits between borderlines, crossing its boundaries, trick-player/deceiver, the cheater, an entity of multiple forms. This article aims to study the nude self-portrait of Schiele from 1910, analyze it e clarify possible similarities found from the comparison between him and the six characteristics from the multicultural and multiformal

Keywords: Egon Schiele, trickster, analysis of images

Trickster created by William Hynes and presented in the chapter Mapping Trickster Characteristics from the book Mythical Trickster Figures.
\end{abstract}


Este presente artigo objetiva realizar a leitura e análise de um dos autorretratos de Schiele, Autorretrato nu de 1910, localizado em Viena, na Graphische Sammlung Albertina e buscar nela e em seu personagem, possíveis aproximações com as características ou traços tricksterianos destacadas por William Hynes.

Acredita-se que a imagem é passível de novas interpretações, e não deve, portanto, congelar-se em determinados olhares. Ela deve sim, ser uma obra aberta, polissêmica, onde se permita criar diálogos ou contiguidades entre a História da Arte e outros campos do conhecimento humano e também entre os textos, implicando acentuada liberdade na análise pessoal do receptor-leitor, como afirma Humberto Eco em Obra aberta.

Há uma ânsia por abrir o olhar, aproximar conceitos e ideias, ressignificando a imagem. Esses, por vezes, improváveis contatos e combinações permitem ampliar a sensibilidade e o conhecimento acerca da produção imagética que se desdobra em diferentes temporalidades e toma novos rumos e construções. A obra será nova obra através de um outro ver, uma outra leitura, uma contaminação.

É necessário e configura-se como tarefa árdua, diante da vasta obra de Egon Schiele, escolher apenas uma imagem a ser analisada. Entretanto justifica-se a escolha do autorretrato, pois segundo Fischer (2007, p.163)

o largo espectro dos auto-retratos de Schiele vai de representações acadêmico-convencionais até provocadoras, desafiando todas as convenções, desde mitologias particulares até à redução a um único gesto ou sentimento, desde a duplicação até à redução a um torso.

Vê-se que eles tratam amplamente do psicológico e do emocional, criando retratos humanos existenciais carregados 
de vida e morte, desejo e sexualidade. Seus autorretratos exploram suas atitudes e características, tanto físicas quanto psicológicas. Concentram toda uma carga expressiva, revelando a maneira com que ele lida com as questões presentes em sua criação poética. Segundo Fischer (2007, p.147) "alegoria, desmascaramento, título de representação e a observação atenta da linguagem do corpo dirigido pelo espírito são aplicados por Schiele principalmente onde o raio das suas pesquisas atinge o maior valor - (...) nos seus autorretratos."

Agora, focando um pouco na figura do artista, pode-se definir este austríaco como exímio autorretratista, cuja obra se situa entre 1908-1918. De personalidade crítica e transgressora, impregnou sua obra com questões como sexualidade, morte e vida, erotismo, o obsceno, a nudez, o sagrado, a pesquisa psicológica do ego e do sujeito, as ambiguidades, a duplicidade, as antíteses e metamorfoses, a gestualidade e qualidades plásticas, gráficas expressivas e também expressionistas.

Suas obras passam por várias fases estilísticas, sempre em constante transformação, assimilando características de outros pintores como Klimt e Kokoschka. Entretanto podemos agrupá-las em duas fases básicas, os anos de 1910 a 1915 e os anos de 1916 a 1918. Segundo Fischer (2007, p.117) os anos de 1910 a 1915 seriam seu auge expressionista e os de 1916 a 1918, seu equilíbrio formal:

provocação e desrespeito dos tabus apresentam-se nos primeiros anos em formas de expressão, angulares e agressivas que não temem a fealdade. A evolução leva o pintor finalmente de volta à uniformidade do traço e às formas básicas da composição clássica.

Nascido em 1890, Schiele é fruto de seu ambiente sócio-cultural. O ambiente em que o artista cresceu e viveu fazia parte do Império Austro-Húngaro que na virada do século, juntamente com Viena, tinha se tornado próspero e tecnologicamente desenvolvido. Viena transformou-se na quarta maior cidade da Europa, entretanto as divisões sociais tornaram-se mais pronunciadas, gerando bairros degradados que eram considerados os piores do continente. Igualmente instável foi a aparente retidão moral que prevaleceu ao longo das cidades europeias naquela época. A sexualidade, considerada incômoda e perigosa, foi afastada da vida pública. Ao mesmo tempo em que os homens se entregavam às inúmeras prostitutas disponíveis, suas mulheres e suas filhas eram protegidas da expo- 
sição a qualquer moral questionável. No início do século XX, artistas e intelectuais expõem desagradáveis verdades que as classes dominantes procuram ocultar. Segundo Short (1997, p. 5) "são precisamente as contradições entre o pessoal e os valores sociais e práticas que são cruciais para nosso entendimento dos momentos-chave na arte e na vida de Schiele."

Dentre os conceitos já abordados, o que se destaca como principal é a idéia de Egon Schiele como um artista transgressor, não se sujeitando as leis morais e cânones artísticos. Pode-se traçar um paralelo entre ele e a figura do trickster.

O termo trickster segundo Hyde (1998, p. 355) é uma invenção da antropologia do século 19 e creditada comumente ao etnologista Daniel Brinton que a introduziu em seu livro The Myths of the New World. Hyde (ibidem) acredita que essa palavra aparece pela primeira vez na antropologia sendo apresentada por Franz Boas, em 1898, no livro Traditions of the Thompson River Indianism. Hynes (1993, p. 14) nos diz ainda que o primeiro uso do termo em inglês remonta também do século 18 (de acordo com o Oxford English Dictionary: 3402), não como uma categoria antropológica, mas para designar moralmente alguém que engana ou trapaceia. No século 19, Benjamim Disraeli o emprega para descrever oponentes políticos mentirosos dentro do Partido Whig. Ricketts (apud HYNES, 1993, p. 14) também menciona o aparecimento do termo em 1868, no livro Myths of the New World, de Daniel Brinton e no século 20, ele tem sido um termo técnico para personagens da literatura européia, bem como para um fenômeno etnográfico, particularmente na América do Norte e África. E hoje o termo se tornou uma designação tão familiar que um autor pode se referir a figura do trickster na Comédia de Aristofanes, a comédia renascentista ou a literatura e filmes contemporâneos.

Dada a sua riqueza, diversidade e complexidade, é muito difícil encapsulá-lo em um único fenômeno. Atualmente teóricos de diversos campos como a Antropologia e a Literatura realizam estudos individuais sobre o trickster, buscando as similaridades entre os diversos tipos e suas funções e trazendo a noção de uma figura genérica, enquanto outros a questionam. Temos aqueles, como Paul Radin, Carl Jung and Karl Kerényi, que afirmam que o trickster representa um arquétipo da psique humana, um estágio primitivo de desenvolvimento da humanidade e outros cientistas sociais procuram identificar essa figura genérica do trickster através de diferentes culturas, vendo características similares em diversas sociedades a partir de um exame comparativo das funções sociais, dos mecanismos 
psicológicos, traços literários, relações entre sistemas religiosos e transformações rituais. A concepção que orientará este artigo é encontrada no livro Mythical trickster figures, onde os ensaístas realizam estudos voltados a um contexto específico, local, histórico ou tribal ou um micro-camadas de manifestações do comportamento particular, vendo-o também como um fenômeno cultural humano, eles buscar revelar as interconexões entre as particularidades e as universalizações.

Dada a sua ampla complexidade, pluralidade e ambiguidade de comportamentos e aparências, mutabilidade e adaptabilidade até mesmo dentro de uma mesma sociedade não se consegue defini-lo dentro uma tipologia estática. Abrahams (apud HYNES, 1993, p.17) afirma que "o trickster (...) é uma figura mais paradoxal de todos os personagens das narrativas ocidentais por ele combinar atributos de vários outros tipos." Ela apresenta vários aspectos ou facetas: pode ser um deus, deusa, espírito, homem, mulher ou animal antropomórfico que prega peças ou de outro modo, desobedece às regras normais e ao comportamento convencional. Aparece como o herói cultural, a anti-herói, o demiurgo, o mensageiro, personagem-animal, o clown, o outsider, o tolo, o piadista, o bufão egoísta, o pícaro, o enganador, o iniciado e transmorfo (HYNES, 1993, p. 24). O termo pode, ainda, ser aplicado a personagens com caracteriristicas tricksterianas.

Alguns exemplos podem ser citados para que haja uma compreensão mais precisa do que vem a ser essa figura: Brer Rabbit, Coyote, Manabozo, Wakdjunkaga (da cultura norte-americana); Eshu (da cultura Yoruba), Ananse, Legba (da cultura africana); Hermes ou Mercúrio, Prometeus, Dionísio (da cultura greco-romana); Susa-no-o, Agu Tampa, Sun Wuk'ung, Horangi, Kitsune (da cultura asiática), o Malandro, o Curupira, o Saci-Pererê (da cultura brasileira). Contemporaneamente presentes nas histórias em quadrinhos, animes, desenhos animados, jogos, filmes e da literatura em geral, temos: Pernalonga, Willy E. Coyote, gato Félix, Naruto, Charles Chaplin, Jack Sparrow, Coringa.

O trickster tem por função o desenvolvimento da criatividade humana, a partir das viagens ao mundo, do amadurecimento do eu, através de desafios e experiências onde a criatividade e a percepção sejam acionadas propiciando mudanças e transformações. Há também o aspecto da destruição que proporciona o conflito e impede que a sociedade fique estagnada. Isso confere a ele o papel de salvador e revolucionário (STREET apud HYNES, 1993, p.19). Turner (apud Hynes, 1993, 
p.20) vê o trickster como alguém que quebra e mistura todas as categorias para causar novas combinações e anomalias. Ambas as ideias se combinam, tornando-o uma fonte potencial de criatividade e perspicácia, contribuindo para o nascimento e a evolução da cultura. Outras funções são a de ser uma "válvula de escape" para as frustrações sociais causadas pelas restrições impostas ou de ser uma espécie de mártir que quebrará os tabus e regras em benefício da humanidade.

Como nos afirma Hynes (1993, p.33) o trickster é um notório transgressor de limites e fronteiras, que é aquele que cruza fronteiras físicas e sociais - é frequentemente um viajante que quebra regras sociais, se rebela contra a autoridade, para questionar e levar-nos a não aceitar as coisas cegamente. Cruzam limites, quebrando ou embaçando conexões ou distinções entre "certo e errado, sagrado e profano, limpo e sujo, masculino e feminino, jovem e velho, vivo e morto". "Visto como uma pessoa suspeita (ou de fora), suas atividade são frequentemente fora-da-lei, estranhas, ultrajantes, fora dos limites e fora da ordem. A falta de limites é sagrada, sendo religiosa, cultural, lingüística, epistemológica ou metafísica” (HYNES, 1993, p.34).

Hynes (1993, p. 34-44) indica a presença de um trickster a partir de seis traços básicos: fundamentalmente ambíguo e anormal, enganador/pregador de peças; metamorfo, "inversor de situações", mensageiro/imitador dos deuses e sagrado e profano "bricoleur". Nem todos eles terão necessariamente que ter todas elas. Embora não se restrinjam às características citadas no capítulo Mapping the characteristics of mythic trickster: a heuristic guide, elas servem-nos como um guia conceitual e metodológico que orientará também nossa leitura e análise de imagens.

1. Fundamentalmente ambíguo e anormal - ele incorpora as contraposições como sagrado e profano, vida e morte, cultura e natureza, ordem e caos, fertilidade e impotência e etc. Remetendo-nos ao princípio filosófico da "coincidência de oposições” de Nicholas de Cusa (apud HYNES, 1993, p. 34). Lévi-Strauss (apud HYNES, 1993, p.34) "vê o trickster como um protótipo de oposições binárias, uma anomalia necessária incorporada a todo um conjunto de oposições." Anormal, ele situa-se no limite de classificações e categorias ou para além deste, é um molde do ser deslocado, que não se prende a fronteiras e limites, suas atividades são fora-da-lei, estranhas, escandalosas, fora dos limites e transita sorrateira e impunemente através de todos os reinos sem permanecer em um único local. Caracteriza-se como um "criativo outsi- 
der" segundo Colin Wilson (apud HYNES, 1993, p, 35), em Outsider de 1956. É mais polivalente do que meramente ambíguo, escapa de qualquer definição restrita, sendo constantemente desmontado e desconstruído.

2. Enganador e pregador de peças - em muitas culturas e religiões ele é o causador de desordens e perturbações, infortúnios e indecências. Verdade e mentira se transmutam rapidamente. Mente, trapaceia, engana atuando como um malicioso "desmancha-prazeres".

3. Metamorfo - altera sua forma ou aparência corporal para facilitar a enganação. Não há limites para transformações de espécies ou de sexualidade, eles são facilmente dissolvidos. As transformações podem ir desde roupas a uma alteração na forma física.

4. Inversor de situações - ele exibe tipicamente a habilidade para sobrepujar qualquer pessoa, lugar ou crença não importa o quão nobre ela for. Não há para ele ordem tão enraizada, tabu tão sagrado, divindade tão poderosa, profanação tão escatológica que não possa ser abordada ou invertida. O que vigora é derrubado e o que é inferior torna-se superior, o que está do lado fora vai para dentro, o que está dentro vai para fora, um encadeamento interminável de contingências. Ele transforma um lugar ou uma situação segura numa perigosa e vice-versa. $\mathrm{O}$ mal ser torna bom, o bom se torna pior, o pior se torna melhor. A tranquilidade torna desastre e faz acontecer seu inverso também. Nada se mantem constante, quanto mais sagrada for uma crença, mais compelido a profaná-la ele será. Alguns deles parecem estar predispostos à criação de uma paródia dos rituais ou uma sátira dos valores dentro de um dado sistema de crenças.

5. Mensageiro e imitador dos deuses - de origem obscura ou impura, o trickster pode ser um mensageiro e um imitador dos deuses. Mistura traços divinos e humanos, podendo mover-se sorrateiramente entre o sagrado e o profano. Ele pode trazer algo dos deuses para os humanos - uma mensagem, punição, ou muito regularmente, dádivas essenciais à humanidade ou a vida em si mesma. Atua como um psicopompo (condutor de almas), um mediador entre as fronteiras e redefine os limites entre vida e morte. Mais comumente associado à restauração da vida, também pode ser o mensageiro da morte. Habitualmente quebrando um tabu crucial estabelecido por ordem divina ele funciona como um transformador cultural.

6. Sagrado e profano bricoleur - o termo bricoleur, empregado no sentido dado por Levi-Strauss, é aquele que trabalha manualmente transformando o que tem acesso 
dando-lhe uma solução criativa. $\mathrm{O}$ autor sugere ainda que o trickster também possa ser um profano ou obsceno bricoleur, pois "ele pode encontrar o profano no sagrado e o sagrado no profano e uma nova vida em ambos" (HYNES, 1993, p. 42). O trickster parece impelido a violar todos os tabus, especialmente aqueles de ordem sexual, gastronômica ou escatológica, por vezes transformando em ocasiões de iluminação, vitalidade e novas criações inventivas.

Resolveu-se adotar o conceito de trickster como artista e transformador, uma imagem de uma potente fonte de criatividade e de iluminação. Doueihi (1998, p. 200) nos diz que "O trickster mostra-nos uma maneira de ver o mundo pela abertura de nossas mentes para as transformações espontâneas da realidade que é sempre aberta e criativa." Como um agente da criatividade e da mudança está associado a atividades ligadas à imaginação, invenção e experimentação, são conseguidas a custa da quebra de tabus. Ou, como afirma Hyde (1998, p.341) o trickster usa o que tem à mão para criar seu próprio mundo. É nesse sentido que o artista torna-se um transmutador e sua arte se realizará pela transmutação das imagens, das coisas e dos significados.

Assim associa-se conceitualmente a figura do trickster a de Egon Schiele, pois ambos são seres transgressores. Aqui se assume que Schiele manifesta-se imageticamente como esse ser. Pode-se trazer para aqui o conceito de artista-personagem, ou seja, o artista expõe sua auto-imagem de um modo peculiar: por meio de uma espécie de "entidade" ou "personagem". Em seus autorretratos o artista transforma um tema geral numa alegoria absolutamente pessoal "e com raízes profundas no inconsciente”. São imagens simbólicas da morte, vida, conversão ou solidão.

Pretende-se analisar semioticamente o Autorretrato nu de 1910, localizado em Viena, na Graphische Sammlung Albertina, com 55,8 x 36,9 cm e posteriormente realizar uma comparação com as seis características tricksterianas desenvolvidas por Hynes.

A semiótica peirceana será usada como subsídio para a leitura e análise das imagens, e apoiar-se-á em alguns de seus conceitos: Primeiridade, Secundidade, Terceiridade e Intersemiose. A primeiridade pede um contato imediato com o signo através da apreensão de suas qualidades. Evoca o acaso, a originalidade irresponsável e livre, a disponibilidade contemplativa, o abrir os "poros" do olhar. A secundidade ligada as presentificações, as singularidades percebidas, aos índices e a terceiri- 
dade ligada a cognição, a síntese, ao crescimento contínuo e ao devir sempre possível pela aquisição de novos hábitos. E a intersemiose, que são as remissões de um signo a outro. Deve-se pensar de que maneira a imagem nos afeta, e descobrir nela associações e relações. O processo intersemiótico contribui para a geração de novos signos a partir dos signos apreendidos.

De acordo com DOTY e HYNES (1993, p. 25) em seu ensaio Historical overview of theoretical issues: The problem of the trickster:

(Uma) análise bem sucedida irá transcender categorias simplistas, permitindo a flexibilidade com a qual se confrontam polaridades, dualidades, e múltiplas manifestações e a complexidade para se para lidar com ambiguidades, ocupações-fronteiriças, paradoxos, a marginalidade, $o$ periférico, a liminaridade, e inversão retratados nas várias caracteristicas tricksterianas.

\section{Análise}

A imagem a seguir é composta por pinceladas bastante gestuais, por vezes soltas, fluidas e agressivas. Sua paleta de cores é formada por tons terrosos, como o amarelo, o laranja, o vermelho e o marrom. Apresenta variações tonais de claros e escuros. Não há muita regularidade, mas as massas de cor são distribuídas de forma a nos dar a noção dos músculos existentes na figura. $\mathrm{O}$ vermelho e o laranja estão nos mamilos, na boca e em outros pontos do corpo; o preto e os tons de marrom encontram-se presentes na cabeleira eriçada, nos pelos do corpo e nas mãos, o preto também constitui as linhas do desenho. Há no centro do peito uma estranha forma aparentando ser uma cavidade em um tom esverdeado. E contornando a figura quase que inteiramente temos o branco que a destaca contra o fundo em papel de tom pardacento.

A linha é crispada, até frágil, apresenta-se irregular, angular, ora curva ora reta, conferindo plasticidade e tensão à imagem. Há nela variações de espessura que visam dar-lhe dinamismo, acentuando certas partes como as mãos e o rosto. $\mathrm{O}$ motivo localiza-se predominantemente à direita, deslocado do centro da imagem e ocupa quase todo o espaço. A composição organiza-se em estruturas similares a triângulos; um grande, pode ser visto na parte superior-central à esquerda, outro, pequeno, na parte central à direita. A linha mestra é quebrada, sendo algo similar a um relâmpago. Aqui predomi- 


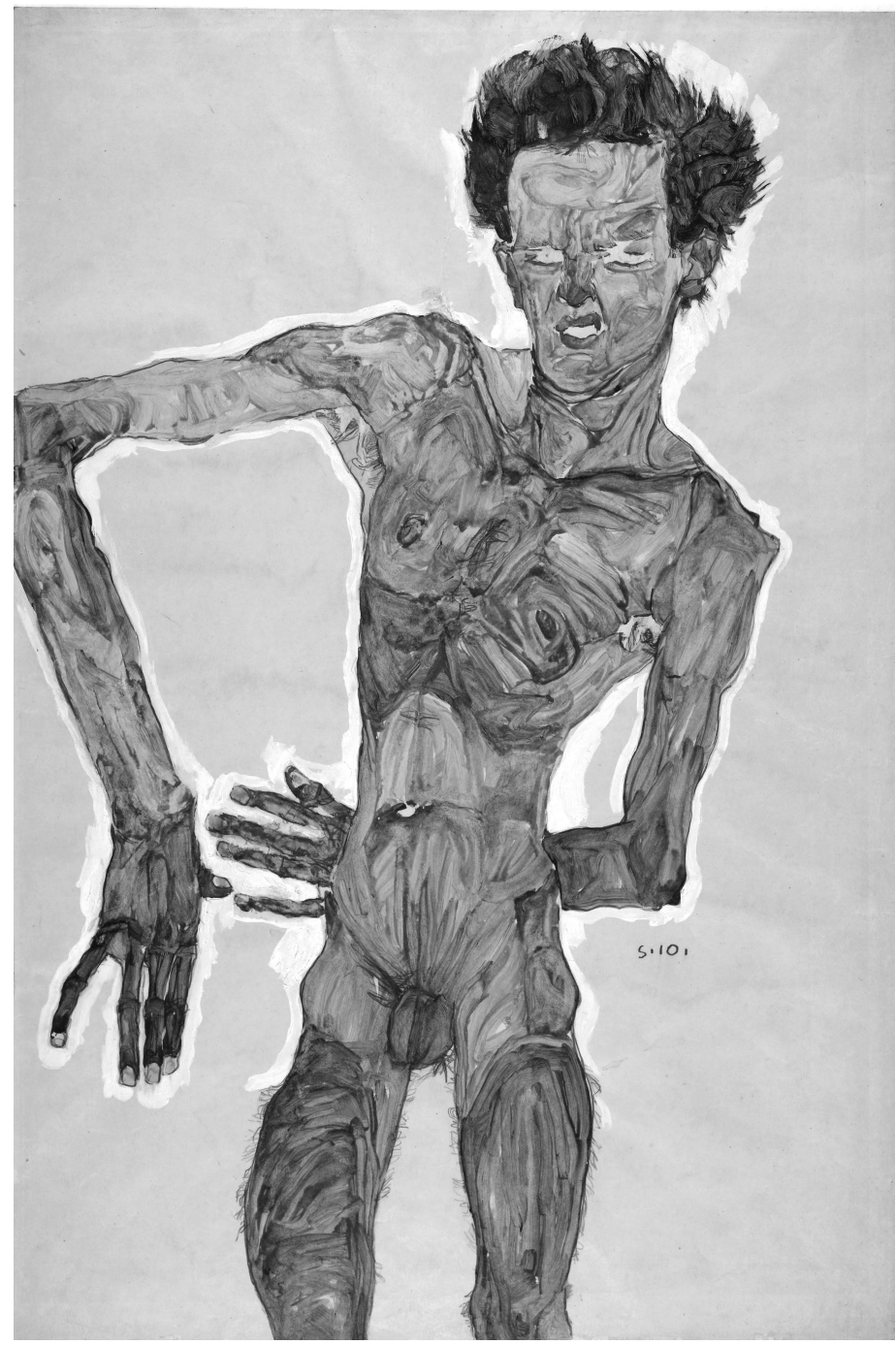

nam os contrastes e movimento, tão característicos da poética de Egon Schiele. Ao invés de harmonia e equilíbrio, procura opostos plenos de tensão. Tudo parece estar sobrecarregado.

Esses elementos gráficos, cromáticos e plásticos são articulados de forma a reforçar antíteses, forças que se opõem e se desestabilizam. Além disso, o artista combina diversas técnicas tais como aquarela, lápis, carvão e guache, criando um hibridismo a partir dessa escolha de linguagens. Aqui já podemos perceber os aspectos da ambiguidade tricksteriana por conta dessas alternâncias e oposições numa mesma iamagem. 
Esse conjunto de signos visuais dá forma a um corpo humano, masculino, jovem, nu e de uma magreza ascética que prima pelas torções e causa estranheza. Suas articulações estão destacadas. O braço direito ergue-se formando um ângulo de $90^{\circ}$, enquanto que o outro membro forma outro ângulo de $90^{\circ}$ em sentido oposto e passa pelas costas do homem. Ele apresenta-se, ao que parece, com as pernas abertas, mas vê-se apenas até um pouco antes de seus joelhos. Os pelos aparecem em algumas partes como que eletrizados, no peito, nas axilas e nas coxas, assim como sua cabeleira castanha-escura. Através das manchas gestuais que formam a pele, tem-se a noção que ela parece ferida ou maculada. A carne e seus músculos parecem ora rijos, tensos e contraídos, ora com uma consistência pastosa ou aquosa que remete a pincelada característica de Schiele. Vê-se um branco luminoso que emoldura o homem e que o isola do espaço físico, dando a impressão de algo espiritual ou místico, de uma aura, um corpo quase astral, que se opõem a carnalidade citada anteriormente. Afirma Steirner (2001, p. 13) que o "emolduramento branco (...) pode ser agora percebido como a aura evocada pela 'luz astral"'.

Seus olhos estão vazados, suas sobrancelhas estão arqueadas e sua boca torcida, num ar de desgosto ou o que parece ser um estado de êxtase ou transe. Sua expressão alterna-se entre dor, raiva, angústia, sofrimento e excitação que não se sabe se é sexual ou místico. Suas mãos e dedos esqueléticos encontram-se abertos, se apresentam com gestos exaltados. Suas expressões faciais e corporais, gestos e posições revelam certa codificação, que lembra os movimentos de uma dança ou de um ritual. Aqui temos novamente a ambiguidade, por conta da alternância e oposição de sentimentos de dor e prazer apresentadas em seu rosto. Temos também a noção de vida e morte em sua tez é de uma cor escurecida que se contrasta com a aura branquíssima que a envolve, evocando oposições como imundice e limpeza, sacralidade e profanação. A beleza da figura é quase grotesca, atrai ao mesmo tempo em que causa repulsa. A anormalidade é vista nas obscenidades da nudez, na desconstrução de si mesmo, na agressividade da aparência e dos gestos, na imagem do erótico, do marginal, do liminar, do excluído, do outsider e do estigmatizado. Ele também cruza as fronteiras espaciais e temporais, está além delas executando uma dança ritualista. Torna-se nesse ponto o inversor de situações e bricoleur sagrado e profano ao atuar no ritual sagrado xamânico através das gestualidades 
e das mímicas, ao transformar-se num ser de forma degenerada, sofrida, angustiada, parar depois tornar-se alguém sagrado e poderoso e vice-versa, pois "ele pode encontrar o profano no sagrado e o sagrado no profano e uma nova vida em ambos" (HYNES, 1993, p. 42).

Esse homem mostra-se frontalmente nu, altamente expressivo, transbordando sexualidade, erotismo e intensidade emocional. Não parece haver contentamento ou satisfação, há apenas a sensação de angústia e de desconforto. Seu corpo frágil revela o isolamento do próprio eu e a angústia interior é exacerbada através dos aspectos formais como a repressão das indicações espaciais e os recursos visuais, como linha e cor. Como afirma Morais (2006, p.41) percebe-se aqui um sujeito atormentado, um homem de sofrimento e com grande fisicalidade. FISCHER (2007, p.165) diz que "pelos, órgão sexual, costelas salientes e articulações destacando (que) os ossos são captados sem embelezamento, numa estilização consciente do repulsivo", causando impacto e transgredindo as normas de moral da "casta" burguesia austríaca. Temos outra vez presentes a ambiguidade e a anormalidade, além de uma consciente quebra de tabus.

O Expressionismo austríaco ao qual pertence Schiele afronta a decência através da decadência. Hatvani (apud STEIRNER 2001, p. 18) revela que "a obra expressionista não está somente ligada à consciência do artista, é idêntica a esta. O artista cria o seu mundo na sua própria imagem.” Tal citação serve para esclarecer os motivos que levaram Egon a figurar entre os expressionistas. Hatvani (apud STEIRNER, 2001, p. 18) complementa ainda dizendo que "deixa de haver exterior: o artista expressionista atualiza a arte de uma forma desconhecida até então... depois dessa interiorização inaudita, a arte deixa de estar submetida a qualquer condição”. A arte torna-se uma crítica às convenções e às normas sociais, uma subversão e um desvio da norma.

Em seu autorretrato o artista-personagem confronta o espectador com sua fealdade, sua nudez, sua obscenidade e suas expressões. Marcuse (apud SCHRÖDER, 2006, p. 46) define a obscenidade a partir de seus efeitos,

a coisa ou pessoa é obsceno se ele, ela, em algum lugar, em algum momento, e por algum motivo, provocar indignação em alguém. Só na presença da indignação que o obsceno torna-se mais do que um fantasma... a indignação específica, mais conhecida por um de seus epítetos preferidos, a abusiva palavra 'obsceno', visa o domínio sexual e áreas contíguas. 
A magreza e deformação raquítica do corpo mostram-se como imagem abjeta da miséria, uma alma mutilada num corpo mutilado. E também afronta a nudez idealizada da beleza grega, que revela perfeição física e mental, a harmonia e o equilíbrio. Essa é uma nudez torturada, um belo-feio como apresenta Argan (2005, p. 240) o "belo decaído, como poética do feio, que se assemelha ao duplo sagrado e demoníaco, espiritual e material. É a beleza do real, que advém da deformação e do uso demoníaco da cor."

Temos aqui diversas características tricksterianas que se completam e se complementam: A ambiguidade da representação, ordem e caos da própria Arte, fertilidade e impotência do ser e outras que já foram citadas anteriormente. A anormalidade mental e física do sujeito que se encontra debilitado. $\mathrm{O}$ aspecto de enganador e o pregador de peças aparecem na quebra de tabus de toda ordem encontrados nessa imagem e que causam desordem e agitação através das transformações propostas pelo estilo de Schiele.

Algo que também chama a atenção são ambiguidade e metamorfose combinadas na representação da genitália da figura, que ora parece com o órgão masculino e ora com o feminino e também na animalização do ser que exibe traços aracnídeos ou mesmo bestiais. Altera facilmente sua forma assumindo diversos papéis, torna-se animalizado e também muda seu sexo. Para ele não há limites para as transformações e dissolvências de barreiras entre espécies ou sexualidade.

A nudez, o descaramento e o exibir consciente do reprimido apresentam oposições à ideia de sexualidade e de inocência, de dissociação entre corpo e espírito, de pecado e moralidade cristãos, como pode-se constatar na passagem bíblica da Genesis 2.25; 3.6-7, que narra a percepção da nudez e o sentimento de vergonha de Adão e Eva. Para Rosenkranz (apud SCHRÖDER, 2006, p. 96) "a obscenidade consiste na violação intencional da decência." Surge neste ponto o aspecto de inversor de situações e de bricoleur sagrado e profano, manifesto na inversão da pessoa e das crenças, na profanação do sexo, da decência e da moralidade. Surge também na questão da subversão no tratamento do gênero autorretrato e do nu, não mais com o véu das alegorias, na utilização das referências iconográficas sagradas ou canônicas, como o homem do sofrimento, na violação de crenças e valores cometidos pelo próprio artista, pondo em xeque o quanto a sociedade é apegada e valoriza tais crenças moralistas e tradicionais, percebida através da rejeição dos críticos. Quanto mais sagrado, maior a tentação 
em profanar, isto é, quanto mais canônico for, maior o desejo em romper essa tradição. Com esse ato, artista e personagem expõe a hipocrisia social, questionam as identidades do sujeito moderno trazendo revolução e mudança.

$\mathrm{O}$ autorretrato criado representa o artista e ao mesmo é uma imagem distorcida de seu eu. A imagem revela outro eu, diferente e desconhecido, um alter-ego, um personagem que questiona, transgride tabus, confronta o homem com seus preconceitos, desafia, cria, pune-se, expõe sua carne, sua feiura, sua sexualidade e sua misogonia. Schiele assume e materializa imageticamente alguns dos aspectos tricksterianos: o herói-cultural, o transgressor, o outsider, o mensageiro dos deuses, o xamã e o mártir.

O doente outsider é um ser repelente e feio, que se ajuste a imagem evocada pelo artista. A imagem é uma des-estetização da estética. Combina-se a isso a expressão de sofrimento vista nos sintomas corporais. O mártir se manifesta na auto-condenação e na estigmatização a que se oferece, transforma-se num ser divino ou amaldiçoado, ligando arte à religiosidade. Segundo Schröder (2006, p. 77) “O imaginário cristão da arte estende a auto-interpretação do artista como demiurgo ao artiste maudit atormentado por dúvidas existenciais."

Também é o mensageiro e imitador dos deuses, roubando a luz ou o fogo destes e sacrificando-se por um "bem coletivo", como no mito de Prometeu. A figura xamânica deste homem apresenta-se através do corpo possuído, isolado do mundo carnal e alienado da realidade. Entrega-se a um frenesi extático durante sua dança ritualística, revelando uma mensagem através de seus gestos e movimentos. É como um deus coberto por uma aura espiritual ou ainda um psicopompo, alguém que transita entre os limites da vida e da morte, restaurando ou destruindo. É alguém com traços humanos e divinos que quebras tabus e as normas sociais cruciais estabelecidos pelas divindades. Sullivan (apud DOTY e HYNES, 1993, p.29) sugere que na paródia tricksteriana todas as pretensões às perfeições, de deuses, figuras institucionais são expostas um patente realismo." Com isso torna-se um herói ou transformador cultural, oferecendo renovação à humanidade.

Ele apresenta-se ainda com um dionisíaco destino vivenciando sua própria tragédia, carregado de embriaguez, num misto de dor e prazer e como um prometeico acorrentado em sua condenação. $\mathrm{O}$ buraco de seu peito parece revelar um vazio. Seria a ausência do coração ou uma brecha para acessá-lo? No mito de Dionísio, após ser cozido e devorado pelos titãs, apenas seu cora- 
ção permaneceu de sua primeira morte e foi suficiente para que Zeus o trouxesse a vida. Percebe-se aqui a possibilidade mítica do renascimento e da transformação manifesta nesse trickster.

\section{Considerações Finais}

Transformação. Esse parece ser o mote do trickster. Transformar, transcender, romper, criar questionamentos e incertezas. Provocar os sujeitos à reflexão. Tal ideia reforça o conceito da própria Arte enquanto produção estética que visa causar estranhamento e desestabilizar.

A obra Autorretrato nu de 1910, uma imagem modernista, permanece ainda muito impactante, mesmo após ser produzida há tantos anos. Escolhida justamente pelo impacto mostrou-se adequada à análise ao representar a figura do artista como um criador interessado em transgredir.

A leitura e a análise da imagem descortinaram as várias ambiguidades contidas no trabalho e o tornaram ainda mais interessante de se analisar. Pode-se atentar ainda para as contradições presentes no ser representado e repensar sobre as próprias contradições presentes em todo o ser humano. Foi extremamente difícil escolher apenas uma obra, pois o olhar foi cada vez mais impregnado pela poética e pelo imaginário do criador. Outra dificuldade encontrada foi separar a imagem-personagem do artista que a concebeu, pois as histórias parecem cruzar-se.

Percebeu-se também a importância da transgressão e da quebra de tabus culturais para transformações na Arte e na sociedade fazendo-a tomar novos ares. Mostrou-se válido buscar uma interpretação diversa da produção de Schiele, ampliando as reflexões sobre seus trabalhos.

Esse estudo abriu, ainda, possibilidades de se pensar paralelos existentes entre a obra de Schiele e os tricksters da mitologia greco-romana Prometeu, Dionísio e Hermes-Mercúrio e também nas manifestações do trickster contemporâneo.

Afirma Hynes (1993, p.8) que o estudo desse material mítico, seus comportamentos e histórias são úteis dentro de nosso próprio contexto, pois frequentemente as brechas e aberturas iniciadas pelos tricksters em seus desafios oferece a sociedade possibilidades de reflexão crítica e de mudanças. Schiele enquanto artista e sua obra desafiaram convenções e tabus de sua época nos propiciarando transformações significativas na Arte. Também nos confrontaram com situações antagônicas, que possivelmente, que nos trariam desejo e repulsa. 
Talvez o trickster seja um dos personagens mais líquidos e fluidos da contemporaneidade, dada a sua territorialização e desterritorialização contínua, suas ambiguidades, sua marginalidade, sua instabilidade e alternância entre vida-morte, entre sagrado-obsceno, entre bom-mau. Mais do que um ser supostamente dual, ele representa o devir, uma constante transformação heraclitiana.

\section{Referências}

ANGEL, Wendy. Artist as Trickster. Disponível em: http://actualart.org/angelwk/text/trickster.html acessado em 23 de Setembro de 2011.

ARGAN, Giulio Carlo. Preâmbulo ao estudo da História da Arte. In: ARGAN, Giulio Carlo; FAGIOLO, Maurizio. Guia de História da arte. Lisboa: Estampa, 1994.

ARGAN, Giulio Carlo. A Arte como expressão. In: Arte Moderna - do Iluminismo aos movimentos contemporâneos. $10^{-}$ reimpressão. São Paulo: Companhia das Letras, 2006. cap. 5. p. 227-253.

ECO, Humberto. Obra aberta. Coleção Debates no 4, 8a ed. São Paulo: Perspectiva, 1991.

FISCHER, Wolfgang Georg. Egon Schiele, 189o-1918: Pantomimas do Prazer, Visões da Mortalidade. Colônia: Taschen, 2007.

HYDE, Lewis. Trickster Makes This World: Mischief, Myth, and Art. Nova York: Farrar, Straus and Giroux, 1998.

HYNES, William J.; DOTY, William G. (Org.). Mythical Trickster Figures, Tuscaloosa: The University of Alabama Press, 1993.

HUSSLEIN-ARCO, Agnes; KALLIR, Jane. Egon Schiele: Self-portraits and Portraits. Nova York: Prestel, 2011.

JUNG, Carl Gustav. On the Psychology of the Trickster Figure. In: RADIN, Paul. The Trickster: A Study in American Indian Mythology. 2a edição. Nova York: Schocken, 1956. p.195-211. . Relação da psicologia analítica com a obra de arte poética. In: O espírito na arte e na ciência. 6a edição. Petrópolis: Editora Vozes, 2011. cap.5. p. 54-72.

LYNTON, Norbert. Expressionismo. In: STANGOS, Nikos. Conceitos da Arte Moderna. São Paulo: Zahar, 2006. p. 24-37.

MAKARIUS, Laura. The myth of the trickster: the necessary breaker of taboos. In: HYNES, William J.; DOTY, William G. (Org.). Mythical Trickster Figures, Tuscaloosa: The University of Alabama Press, 1993. cap.5. p. 66-86. 
MORAIS, Zita. Egon Schiele. Lisboa: Lisma, 2006.

NADELBERG, Laura R. Cultural Heroes and Mirrors of Darker Desires: Transitioning Tricksters of Our Past into Contemporary Society. Anthropology Department Honors Papers, Connecticut College. 2008. Disponível em: http:// digitalcommons.conncoll.edu/anthrohp/1 acessado em 23 de Setembro de 2011.

RADIN, Paul. The Trickster: A Study in American Indian Mythology. 2a edição. Nova York: Schocken, 1956.

SANTAELLA, Lúcia. O que é Semiótica. 23를 reimpressão. São Paulo: Brasiliense, 2006.

SCHRÖDER, Klaus Albrecht. Egon Schiele, Eros and Passion. $1^{\underline{a}}$ edição. Nova York: Prestel Verlag, 2006.

SHORT, Christopher. Schiele. Nova York: Phaidon, 1997.

STEIRNER, Reinhard. Egon Schiele, 1890-1918: A alma noturna do artista. Colônia: Taschen. 2001.

WHITFORD, Frank. Egon Schiele. Nova York: Thames \& Hudson, 2006.

Recebido em: 12/12/11

Aceito em: 13/05/13

\footnotetext{
DANIEL FRANCO DE OLIVEIRA

danielfranco_vr@hotmail.com

Possui graduação em Artes Visuais pelo Centro Universitário de Barra Mansa (2008). Atualmente é professor do ensino básico federal do Colégio Brigadeiro Newton Braga no Rio de Janeiro e tutor presencial da Fundação Centro de Ciências e Educação Superior à Distância do Estado do RJ.
} 